\title{
A Comparative Study between a Conventional Two-Level and a Flying Capacitor Four-level VSI for Use in Four-Wire Shunt APF Applications
}

\author{
A. F. Hanna Nohra ${ }^{1,2,3}$, M. Fadel ${ }^{2,3}$ and H. Y. Kanaan ${ }^{1}$ \\ ${ }^{1}$ St-Joseph University, Faculty of Engineering - ESIB, Mar Roukoz, Mkalles, B.P. 11-0514, Beirut 1107 2050, Lebanon \\ ${ }^{2}$ Université de Toulouse ; INPT, UPS ; ENSEEIHT, 2 rue Charles Camichel, BP 7122, F-31071 Toulouse cedex 7, France \\ ${ }^{3}$ CNRS ; LAPLACE ; F-31071 Toulouse, France \\ antoine.hanna.nohra@laplace.univ-tlse.fr, maurice.fadel@laplace.univ-tlse.fr, hadi.kanaan@usj.edu.lb
}

\begin{abstract}
Shunt Active Power Filters (SAPF) are proposed for Power Quality (PQ) improvement in perturbed power distribution networks. Conventionally, the 2-level Voltage Source Inverter (VSI) topology is used in three-phase four wire power distribution networks to mitigate current harmonics and to enhance Power Factor (PF). The Multilevel Inverter (MI) such as the Flying-Capacitor (FLC) topology is competitive with the conventionally inverters for the same targets on low voltage domain, in addition to its performance in medium voltage. In this work a comparative study of two SAPF topologies is proposed. We compare the performance for the two structures for the same modulation, same current and voltage regulation method, same control strategy using modified formulation of the $p-q$ strategy. Firstly, it is demonstrated that the neutral current can be reduced in the conventionally 2-level structure by using a Phase Shift PWM (PSPWM) modulation instead of Sinusoidal PWM (SPWM) modulation. Secondly, peaks of source currents are reduced in the transient state by action on the Pass Band of the DC voltage regulator. Thirdly, comparison between the sizes of the inductance of the filters is made, voltage stresses on the electronic components are compared and harmonic generated by the output voltages of VSI are compared. It is demonstrated the superiority of the FLC over the two-level topology.
\end{abstract}

\section{Keywords}

Active power filter, VSI, FLC, modified $p-q$ theory, harmonics.

\section{Nomenclature and Formulas}

$\begin{array}{ll}\text { SAPF } & \text { Shunt Active Power Filter } \\ A P F & \text { Active Power Filter } \\ P Q & \text { Power Quality } \\ V S I & \text { Voltage Source Inverter } \\ P F & \text { Power Factor } \\ M I & \text { Multilevel Inverter } \\ F L C & \text { Flying Capacitor } \\ \text { PSPWM } & \text { Phase Shift Pulse Width Modulation } \\ \text { SPWM } & \text { Sinusoidal Pulse Width Modulation } \\ v_{i n v} & \text { Output voltage of the inverter } \\ V_{i n v} & \text { Average value of the filter's output voltage } \\ G_{i n v} & \text { Gain of the inverter } \\ f & \text { Frequency of the voltage source } \\ f_{s w} & \text { Switching frequency }\end{array}$

PB Pass Band

$f_{P B} \quad$ Pass band frequency

THD Total Harmonic Distortion

$T H D_{x}=\frac{\sqrt{\sum_{h=2}^{\infty} X_{h}^{2}}}{X_{1}}$

\section{Introduction}

Nonlinear loads such, as televisions, compact fluorescent lamps, personal computers and multimedia devices, phone chargers and battery charger for electric vehicle in addition to more other tertiary sector and industrial loads, are increasingly used in power distribution networks. All this devices absorb a non-sinusoidal current that increases the current and voltage Total Harmonic Distortion (THD) [1-4], generates a noticeable circulating current in the neutral line [5], and causes additional losses in the power transmission lines and transformers [6-9]. It is demonstrated in [10] that the voltage distortion can exceed levels set by IEEE 519 [11] due to the progressive use of nonlinear devices.

The SAPF was already presented as a solution for improving PQ [12-21]. But researches are needed to improve the quality of filtering.

Pulse Width Modulation PWM [22-23], is used for a VSI and MI. In this paper, we propose the Phase Shift PWM (PSPWM) modulation scheme for the VSI based-on three carriers shifted of $120^{\circ}$ like as the modulation control for a FLC. This control insures a good control for the neutral current on the side of the source and permits a fair comparison with the FLC.

And more, in this work, a comparison on the performance of the two structure is studied on term of sizing of filter inductance, on the harmonic distortion of source currents and finally on the electronic component constraints.

This paper is organized as follows. In section 2, the SPWM and PSPWM are presented but slightly modified in order to obtain the gain of converters. Consequently, the current regulation scheme is done. In section 3, DC voltage regulation and control law for both structures are presented. 
In fact, a new control strategy was developed and validated in a previous work [24-25]. In this paper, just a summary is given about this control strategy.

In section 4 a comparison is made on the performance of SAPF on PSPWM modulation scheme and classical SPWM. It is demonstrated in this section that the PSPWM is better than the SPWM for active filter operation. More, performance of the simulation based on the Pass Band of the DC voltage regulator is discussed. Also, in this section, the comparison between conventionally VSI and FLC VSI is made. The simulation results using the Psim tool are presented and discussed. The paper finally ends with some concluding remarks in section 5 .

\section{Modulation Techniques}

\section{A. Sinusoidal PWM}

In the classical SPWM, The VSI converter is controlled using one carrier modulation strategy compared to the three reference signals illustrated in Fig. 1.

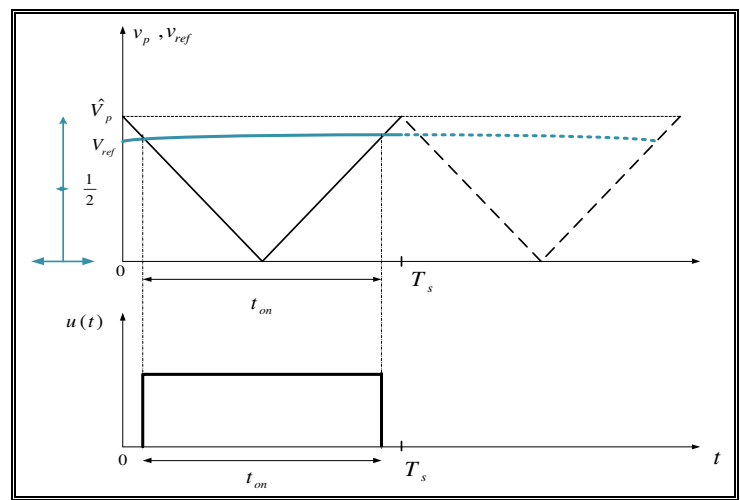

Fig. 1. PWM for one reference.

The average value of the control signal $u(t)$ on a switching period $T_{s}$ is therefore:

$$
<u(t)>=\frac{1}{T_{S}} \int_{0}^{T_{S}} u(t) \cdot d t=\frac{t_{\text {on }}}{T_{S}}
$$

The duty cycle is given by:

$$
\alpha=\frac{t_{\text {on }}}{T_{s}}=\frac{V_{r e f}}{\widehat{V}_{p}}=<u(t)>
$$

The average value of the output voltage of the inverter $v_{i n v}$ on a switching period $T_{s}$ is therefore:

$$
V_{\text {inv }}=\frac{E}{2}(2 . \alpha-1)
$$

Replacing (2) on (3) and assuming that:

$$
\widehat{V}_{p}=1
$$

The average voltage of the inverter becomes:

$$
V_{i n v}=\frac{E}{2}\left(2 \cdot V_{r e f}-1\right)
$$

We can make a translation of $1 / 2$ for the $v_{\text {ref }}$ presented on Fig. 2.

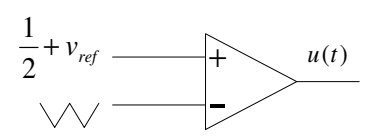

Fig. 2. Modification of $v_{\text {ref }}$.

The new reference is presented on Fig.3.

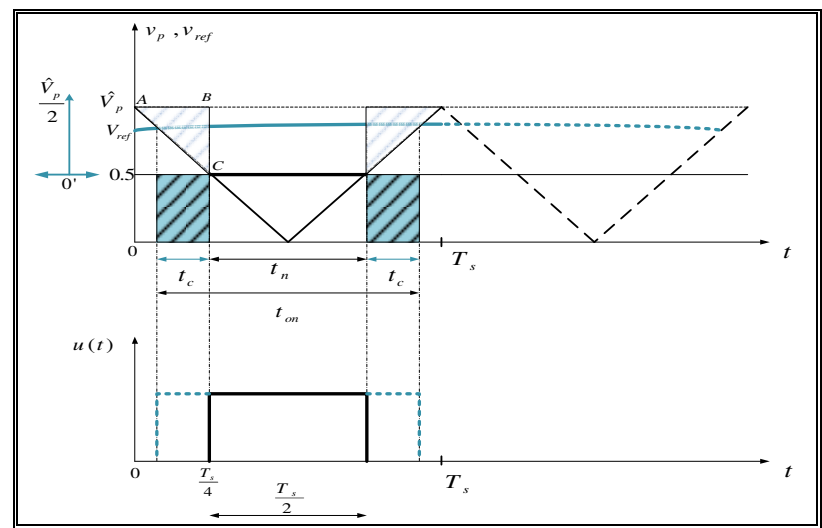

Fig. 3. Translation of the reference.

According to which we may set:

$$
\alpha=\alpha_{n}+\alpha_{\text {ref }}
$$

With, the naturally duty cycle:

and:

$$
\alpha_{n}=\frac{t_{n}}{T_{S}}=\frac{\frac{T_{S}}{2}}{T_{S}}=\frac{1}{2}
$$

$$
\alpha_{\text {ref }}=\frac{2 . t_{c}}{T_{s}}=\frac{V_{r e f}}{\widehat{V}_{p}}
$$

Then:

$$
\alpha_{\text {ref }}=\alpha-\frac{1}{2}
$$

From (3) and (9), we can write:

$$
V_{i n v}=\frac{E}{2}(2 \cdot \alpha-1)=\frac{E}{2}\left(2 \cdot\left(\alpha_{r e f}+\frac{1}{2}\right)-1\right)=\alpha_{r e f} \cdot E
$$

Finally, by using (8) and (4) on (10), we obtain:

$$
V_{i n v}=V_{\text {ref }} \cdot E
$$

The gain $G_{i n v}$ of the filter is:

$$
G_{\text {inv }}=\frac{V_{\text {inv }}}{V_{\text {ref }}}=E
$$

\section{B. Phase shift PWM}

For the VSI Fig. 9, the new command consists on employing three carriers shifted by 120 degrees and compared to the three reference signals. The resulting control signals $u_{1}(t), u_{2}(t)$ and $u_{3}(t)$ are generated for each carrier. It is assumed that the switching frequency is much higher than the reference frequency. 
For an FLC inverter with a three-cell structure, three carriers shifted by 120 degrees are employed and compared to the same reference signal. Three resulting control signals $u_{1}(t), u_{2}(t)$ and $u_{3}(t)$ are generated. By assuming the switching frequency much higher than the reference frequency, the conducting periods of the switches are practically equal on a switching cycle $T_{s}$, i.e.:

$$
t_{1 o n}=t_{2 o n}=t_{3 o n}=t_{\text {on }}
$$

It yields:

$$
\alpha_{1}=\alpha_{2}=\alpha_{3}=\alpha
$$

This assumption is essential for the operation of the FLC to ensure a natural balancing of the split DC voltages [39].

\section{Electrical model for the filter}

The electrical equation for the filter is:

with:

$$
v_{i n v}-v_{s}=L_{f} \frac{d i_{f}}{d t}
$$

$$
v_{i n v}=G_{i n v} \cdot v_{r e f}
$$

These equations are represented by the block diagram in Fig. 4.

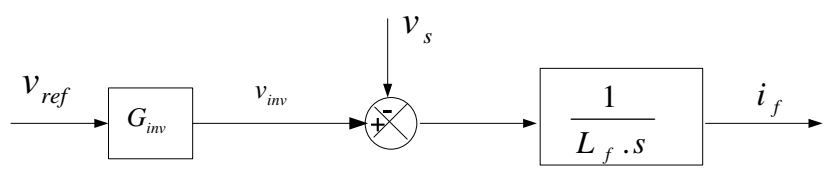

Fig. 4. Electrical model for one phase of the filter.

The grid voltage $v_{s}$ constitutes a perturbation for the transfer function $\frac{i_{f}}{v_{r e f}}$ which is compensated for as shown in Fig. 5.

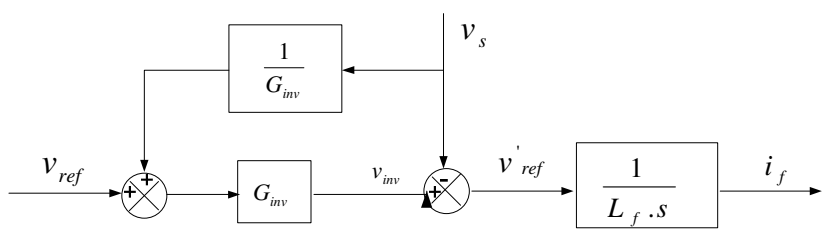

Fig. 5. Compensation of the source perturbation.

It yields:

$$
v_{r e f}^{\prime}=\left(v_{r e f}+\frac{v_{s}}{G_{i n v}}\right) \cdot G_{i n v}-v_{s}=v_{r e f} \cdot G_{i n v}
$$

The transfer function can be then written:

Then:

$$
\frac{i_{f}}{v_{r e f}^{\prime}}=\frac{1}{L_{f} \cdot s} \Rightarrow \frac{i_{f}}{v_{r e f}}=\frac{G_{i n v}}{L_{f} \cdot s}
$$

$$
\frac{i_{f}}{v_{r e f}}=\frac{G_{i n v}}{L_{f} \cdot S}=\frac{E}{L_{f} \cdot S}
$$

\section{DC Voltage Regulation and Control Strategy}

\section{A. DC voltage regulation}

For the harmonics filtering and PF compensation, there is no need for energy storage on the capacitor. Otherwise, the capacitor would need an active power to replace energy used to compensate the losses on the filter. This leads to stabilize the DC bus voltage. The energy stored on the capacitor is:

$$
w=\frac{1}{2} \cdot C \cdot V^{2}
$$

That gives for the instant power:

$$
p=\frac{d w}{d t}=\frac{1}{2} C \cdot \frac{d V^{2}}{d t}
$$

By setting:

it yields:

$$
X=V^{2}
$$

$$
p=\frac{1}{2} C \cdot \frac{d X}{d t}
$$

and, in the Laplace domain:

$$
P(s)=\frac{1}{2} C . S . X(s)
$$

The transfer function is:

$$
\frac{X(s)}{P(s)}=\frac{2}{C . s}
$$

On the other hand, the total power absorbed at the source for the two capacitors is:

$$
P=\frac{3 \cdot \widehat{V} \cdot \hat{I}}{2}=\frac{3 \cdot \widehat{V} \cdot \hat{I}_{f}}{2}
$$

For one capacitor:

$$
P=\frac{3 \cdot \widehat{V} \cdot \hat{I}_{f}}{4}
$$

The block diagram in Fig. 6 illustrates this regulation, with:

and:

$$
k_{p}=\frac{2 \cdot C \cdot \omega_{P B}}{3 \cdot \widehat{V}}
$$

$$
T_{i}=\frac{\sqrt{10}}{\omega_{P B}}
$$

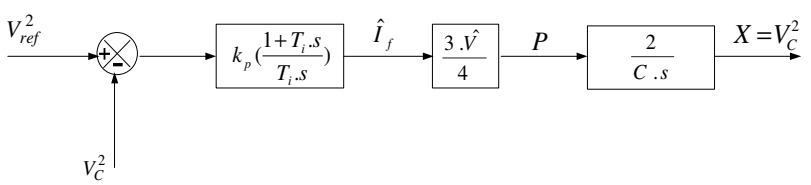

Fig. 6. Bloc diagram for the regulation of the DC voltage.

\section{B. Control strategy}

A new expression of the reference currents is developed in the method described in [24-25].This method is based on 
the separation of the zero sequence current from the zero sequence power in the case of balanced voltages and unbalance and distorted currents, which has permitted to control an equal repartition of the zero-sequence current component within the three phases of the supply distribution network yielding, thereby, the elimination of the neutral current. A brief description of this method follows.

Powers in the $\alpha \beta$ frame are given by the following equation:

$$
\left[\begin{array}{l}
p \\
q
\end{array}\right]=\left[\begin{array}{cc}
v_{\alpha} & v_{\beta} \\
-v_{\beta} & v_{\alpha}
\end{array}\right] \cdot\left[\begin{array}{l}
i_{\alpha} \\
i_{\beta}
\end{array}\right]
$$

Current references in $\alpha \beta$ frame are consequently given by:

$$
\left[\begin{array}{l}
i_{\alpha}^{*} \\
i_{\beta}^{*}
\end{array}\right]=\frac{1}{v_{\alpha}^{2}+v_{\beta}^{2}} \cdot\left[\begin{array}{cc}
v_{\alpha} & -v_{\beta} \\
v_{\beta} & v_{\alpha}
\end{array}\right] \cdot\left[\begin{array}{c}
\tilde{p}+p_{C} \\
-(\bar{q}+\tilde{q})
\end{array}\right]
$$

The current references in $a b c$ frame are computed as:

$$
\left[\begin{array}{l}
i_{a}^{*} \\
i_{b}^{*} \\
i_{c}^{*}
\end{array}\right]=\sqrt{\frac{2}{3}} \cdot\left[\begin{array}{ccc}
0 & 1 & 0 \\
0 & \frac{-1}{2} & \frac{\sqrt{3}}{2} \\
0 & \frac{-1}{2} & \frac{-\sqrt{3}}{2}
\end{array}\right] \cdot\left[\begin{array}{c}
0 \\
i_{\alpha}^{*} \\
i_{\beta}^{*}
\end{array}\right]+\left[\begin{array}{ccc}
\frac{1}{3} & 0 & 0 \\
\frac{1}{3} & 0 & 0 \\
\frac{1}{3} & 0 & 0
\end{array}\right] \cdot\left[\begin{array}{c}
i_{n} \\
0 \\
0
\end{array}\right]
$$

The block diagram in Fig.7 illustrates this method, where $P_{c}$ represents the losses power. Fig. 8 represents the scheme of the regulation of current.

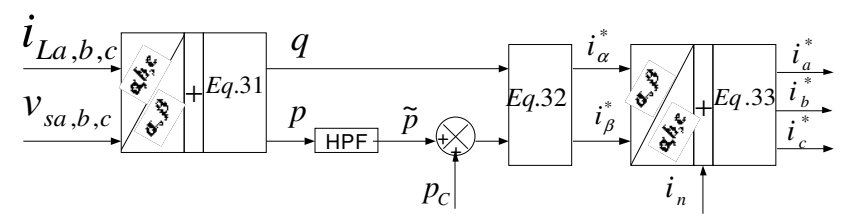

Fig. 7. Block diagram for reference currents extraction.

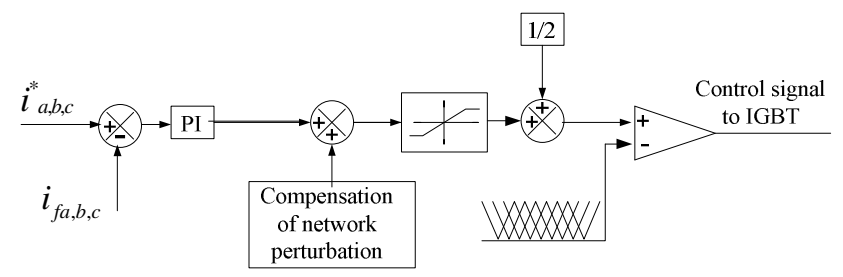

Fig. 8. Block diagram for current regulation and modulation.

\section{Simulation Results and Discussions}

All experiments are made with the following numerical values:

- Source: $\widehat{V}=310 \mathrm{~V}, f=50 \mathrm{~Hz}$

- 2-level VSI inverter : $C=1 m F, L_{f}=12 m H$

- FLC inverter: $C=1 \mathrm{mF}, L_{f}=2 \mathrm{mH}$

- Modulation frequency: $f_{s w}=10 \mathrm{kHz}$

- Regulators: $f_{p b i}=3 \mathrm{kHz} . f_{p b v}=300 \mathrm{~Hz}$

- Resistive loads: $R_{l a}=6 \Omega, R_{l b}=8 \Omega, R_{l c}=10 \Omega$

- Common load: $L_{1}=6 \mathrm{mH}, R_{2}=0.5 \Omega, L_{2}=20 \mathrm{mH}$, $C=1500 \mu F$

\section{A. Effect of the voltage loop crossing frequency}

A good filtering is the result of a compromise between the method of reference currents extraction, modulation and regulators for currents and voltages. In what follows, we consider that the current absorbed by the capacitors, for the compensation of losses, is passed through the diodes of the inverter and its frequency is $6 f$. Then, the crossing frequency of the DC voltage regulator is chosen for $f_{p b v}=300 \mathrm{~Hz}$. Fig. 9 illustrates the three levels FLC based on APF.

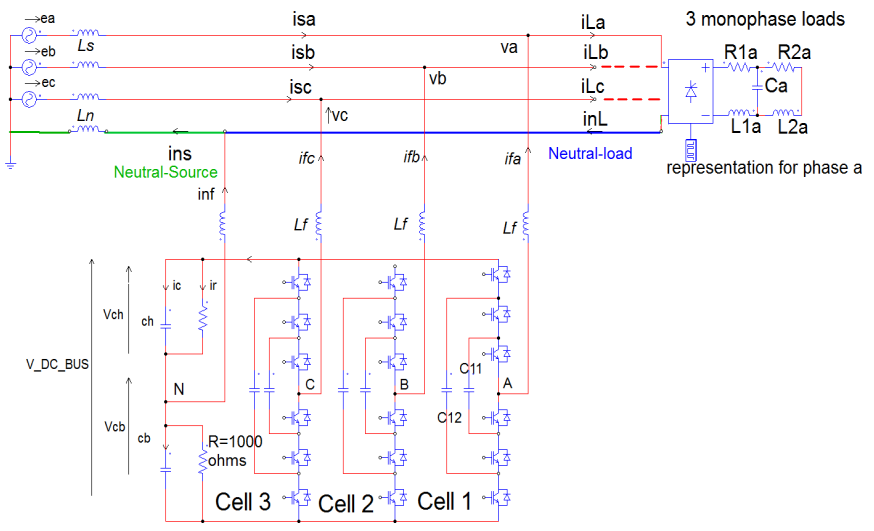

Fig. 9. Three cells, four-wire, four-level FLC APF.

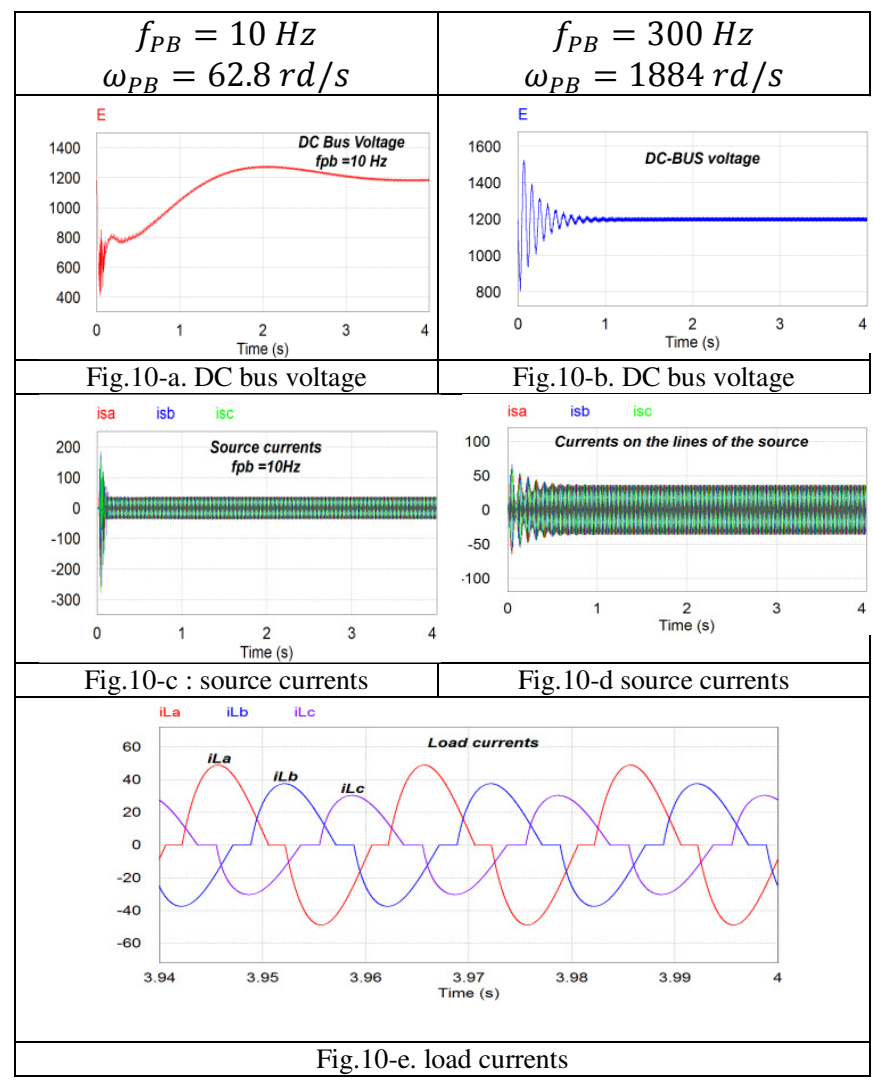

Fig. 10. Impact of the pass band of DC voltage regulator.

In Fig. 10, a comparison between two crossing frequencies for the voltage regulator shows that $f_{p b v}=300$ $\mathrm{Hz}$ (Figs. 10.b and 10.d) is better than $f_{p b v}=10 \mathrm{~Hz}$ (Figs. 10.a and 10.c). For a smaller crossing frequency, the time response for the DC-bus voltage is obviously longer, and 
the peaks on source currents are greater. In the following, $f_{p b v}=300 \mathrm{~Hz}$ is adopted for simulations.

In Fig. 10.e, the load currents are show and, in Table 2, their THD values are given.

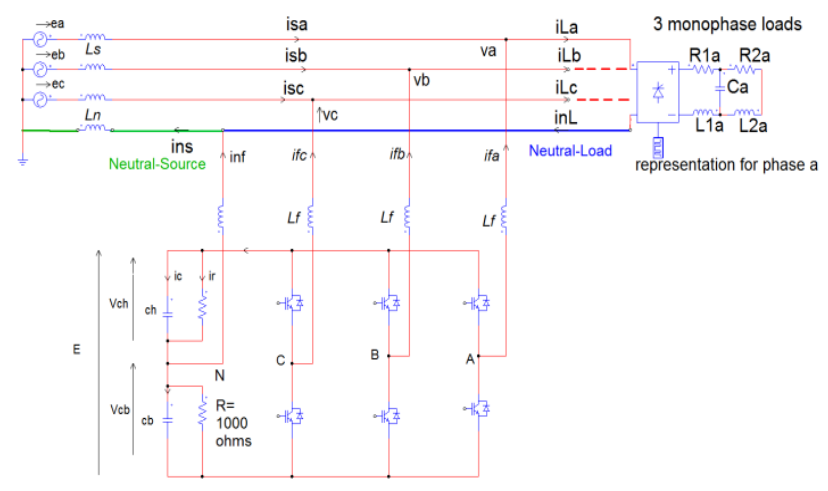

Fig. 11. VSI 2-level scheme on APF application.

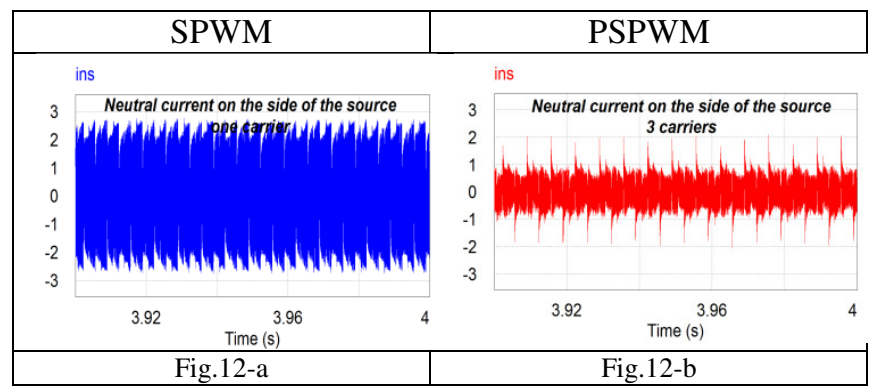

Fig. 12. Comparison between neutral currents.

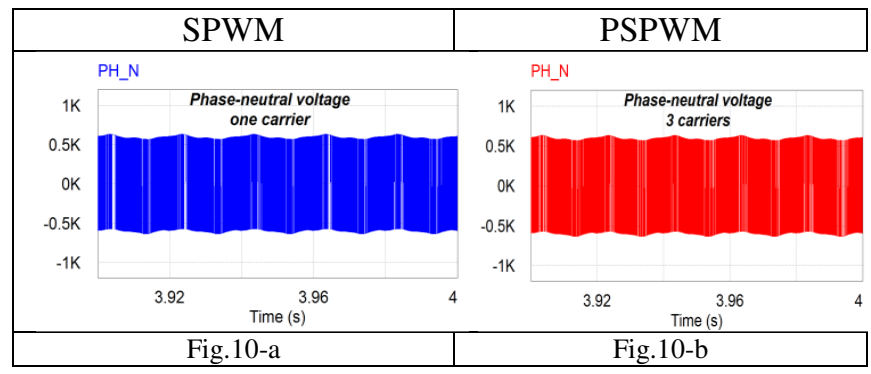

Fig. 13. Comparison between phase-neutral voltages for the two modulation techniques.

\section{B. Comparison between the SPWM and PSPWM}

The signal references for the APF come from the current regulator and they are perturbed. In the case where one carrier is used for the three references, we don't have precision on times commutation. It is for this reason that we use three carriers, one for each signal reference, that yielding for a better control for the neutral current.

Fig. 11 represents the VSI on APF application for four wire power distribution network.

In Fig. 12, neutral currents on the side of the source are compared for the tow modulation techniques. It is shown that the PSPWM offer a good control for the neutral current Fig.12.b.

In Fig. 13, the phase-to-neutral voltage are also compared and that show that no big modification on the output voltages. But in Table 1 and Table 2, values of harmonics components and respectively the THD values of source currents give an advantage for the PSPWM. All these results highlight the superiority of the PSPWM over the SPWM for a VSI in APF application.

\section{Comparison between the VSI and FLC}

Once we have the same modulation, the same control strategy and the same voltage regulator, the comparison on the structures is fairly carried and gives a better appreciation. The main difference is on the size of the filter inductance. Fig.14 shows that the performance of the two structures cannot be approached except for a value of filter inductance for the 2-level equal to 6 times that of the FLC. Figs. 14.a and 14.b show the source currents for, respectively, 2-level and FLC and in Table 2, the THD values prove the excellent advantage of the FLC. In Fig. 14.d, neutral current on the source side for an APF basedon FLC is more reduced than that the neutral current for 2 levels VSI on Fig. 14.c. Harmonic contents within the phase to neutral voltage Figs. 14.e and 14.f are in the interest of the FLC and more, the first harmonic appears at $3 f_{s w}$ for the FLC in Fig.14.f and at $f_{s w}$ in Fig.14.e for the 2level topology. In Fig.14.g and Fig. 14.h, the spectrum of the IGBT voltage shows that amplitudes of harmonics in the FLC (200 V for DC component) are lower than that the 2-level $(600 \mathrm{~V}$ for DC component). This result means that the harmonic stress on the IGBT of FLC topology is much reduced. It is a main advantage for a multilevel inverter.

\section{Conclusions}

In this work, a comparison is made between two topologies of VSI for SAPF application. It is validate by simulation for the FLC use that the neutral current on the side of the source is reduced more than that the 2-levels. Harmonic distortion of the source currents is also more reduced. These results are obtained with initially improvement for the functioning of the 2-level by using the PSPWM instead the SPWM modulation. The size of the filter inductor for a FLC is much smaller than that the 2-levels. Small amplitude of harmonic on the output voltage of the filter and the frequency of the first harmonic $\left(3 \mathrm{x} f_{s w}\right)$ for the FLC leads to sizing a small output filter. The maximum of the voltage across IGBTs is reduced three times for the FLC versus the 2-levels. The FLC topology is shown to be better than the 2-level conventional inverter for APF applications.

\section{Acknowledgements}

This work has been supported by the National Council for Scientific Research, Lebanon (CNRS-L), the Agence Universitaire de la Francophonie (AUF), the PHC CEDRE 2014 project $N^{\circ} 30108 X K$, the Research Council of SaintJoseph University, Beirut, Lebanon, and the laboratory LAPLACE. The authors also wish to thank gratefully the Institut Français of the French Embassy in Lebanon and the Institut Supérieur des Sciences Appliquées et Economiques (I.S.S.A.E-Cnam Liban) for their financial contribution. 


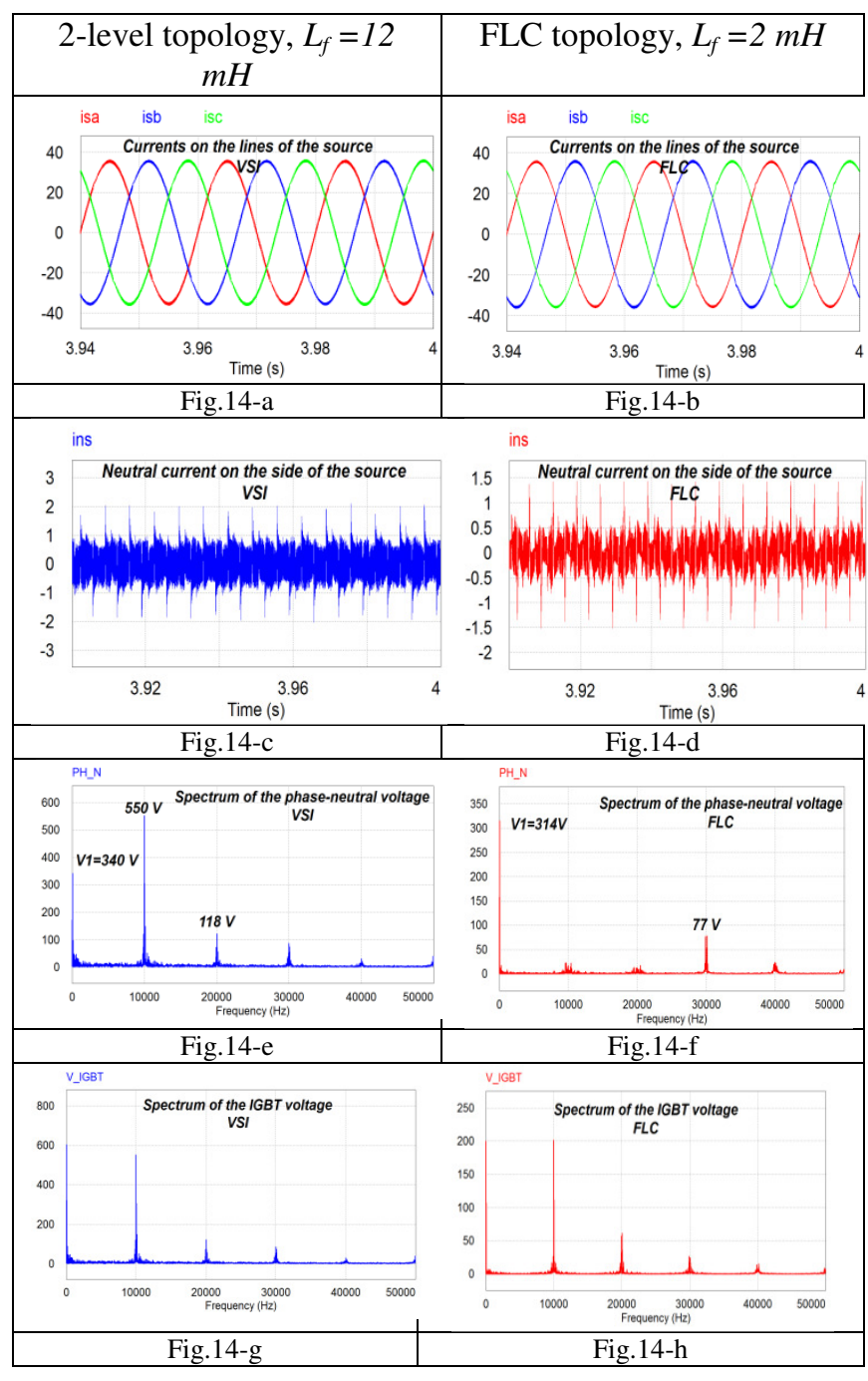

Fig. 14. Comparison between a VSI 2-levels and FLC.

Table 1: Harmonic components for the phase to neutral voltage.

\begin{tabular}{|c|c|c|}
\hline \multicolumn{3}{|c|}{ Phase -neutral voltage } \\
\hline harmonics & SPWM & PSPWM \\
\hline $50 \mathrm{~Hz}$ & 338 & 340 \\
\hline $150 \mathrm{~Hz}$ & 91 & 90 \\
\hline $250 \mathrm{~Hz}$ & 32 & 35 \\
\hline $350 \mathrm{~Hz}$ & 54 & 31 \\
\hline $450 \mathrm{~Hz}$ & 36 & 14 \\
\hline $550 \mathrm{~Hz}$ & 60 & 50 \\
\hline $10 \mathrm{kHz}$ & 558 & 551 \\
\hline 19950 & 74 & 73 \\
\hline 20050 & 126 & 118 \\
\hline
\end{tabular}

Table 2: Comparative values of THD for the source currents.

\begin{tabular}{|c|c|c|c|c|c|}
\hline \multirow{2}{*}{$\begin{array}{c}\text { Load } \\
\text { currents }\end{array}$} & \multirow{2}{*}{ THDi } & \multirow{2}{*}{$\begin{array}{c}\text { Source } \\
\text { currents }\end{array}$} & $\begin{array}{c}\text { SPWM } \\
\text { 2-level }\end{array}$ & $\begin{array}{c}\text { PSPWM } \\
\text { 2-level }\end{array}$ & $\begin{array}{c}\text { PSPWM } \\
\text { FLC }\end{array}$ \\
\hline iLa & $17 \%$ & isa & $2.35 \%$ & $2.29 \%$ & $1.42 \%$ \\
\hline iLb & $18 \%$ & isb & $2.32 \%$ & $2.24 \%$ & $1.49 \%$ \\
\hline iLc & $19 \%$ & isc & $2.36 \%$ & $2.29 \%$ & $1.38 \%$ \\
\hline
\end{tabular}

\section{References}

[1] Sharma, H.; Sunderman, W.G.; Gaikwad, A., "Harmonic impacts of widespread use of CFL lamps on distribution systems," Power and Energy Society General Meeting, 2011 IEEE, vol., no., pp.1,5, 24-29 July 2011.
[2] J. Cunill-Sola, J. J. Mesas and L. Sainz, "Low-watt compact fluorescent lamps with electronic Ballasts", POWERENG'11, Malaga, Spain, May 2011, pp. 1-5.

[3] A.F.Hanna Nohra.; Kanaan, H.Y.; Al-Haddad, K., "A study on the impact of a massive integration of compact fluorescent lamps on power quality in distribution power systems," International Conference on Renewable Energies for Developing Countries (REDEC), 2012, vol., no., pp.1,6, 28-29 Nov. 2012

[4] PengXin; Zhang Zhebo, "Analysis of electric vehicles' impact to the electric grid," International Conference on Electricity Distribution (CICED), 2012 China, vol., no., pp.1,5, 10-14 Sept. 2012

[5] J. J. M. Desmet, I. Sweertvaegher, G.Vanalme, K. Stockman and R. J. M. Belmans, "Analysis of the Neutral Conductor Current in a Three-Phase Supplied Network With Nonlinear Single-Phase Loads", IEEE Trans. Industry Appl., vol. 39, No. 3, May/June 2003, pp. 587-593.

[6] A. Gupta and R. Singh, "Evaluation of Distribution Transformer Losses Under Harmonic Loads Using Analytical and Simulation Methods", International Journal on Emerging Technologies, vol.2, No. 2, 2011, pp. 90-95.

[7] M. Masoum, P. S. Moses and A. S. Masoum, "Derating of Asymmetric Three-Phase Transformers Serving Unbalanced Nonlinear Loads", IEEE Trans. Power Delivery, vol.23, No. 4, Oct. 2008, pp. 2033-2041.

[8] C. R. Pacheco, J. C. de Oliveira and O. C. N. Souto, "Insulated Cable Thermal And Life Expectancy Estimation Under NonSinusoidal Operating Conditions", DRPT'00, 2000, pp. 672-677.

[9] IEEE Recommended Practice for Establishing Transformer Capability When Supplying Non-sinusoidal Load Currents, ANSI/IEEE Std. C57.110-1986, 1988.

[10] McBee, K.D.; Simoes, M.G., "Evaluating the long-term impact of a continuously increasing harmonic load demand on feeder level voltage distortion," Industry Applications Society Annual Meeting (IAS), 2012 IEEE, vol., no., pp.1,8, 7-11 Oct. 2012

[11] IEEE Recommended Practice and Requirement for Harmonic Control in Electrical Power systems. IEEE Std.519-1992

[12] H. Y. Kanaan, I. Mougharbel and K. Al-Haddad, "Average Modeling and Carrier-Based Control Strategies Applied to a Three-Phase Four-Leg Shunt Active Power Filter", International Review of Electrical Engineering (IREE), Praise Worthy Prize (PWP), vol.3, No.5, October 2008, pp. 443-451.

[13] S. Rahmani, K. Al-Haddad, H. Y. Kanaan and B. Singh, "Implementation and Simulation of Modified PWM with Two Current Control Techniques Applied To Single-Phase Shunt Hybrid Power Filter", IEE Proceedings - Electric Power Applications, Vol. 153, No. 03, May 2006, pp. 317-326.

[14] B. Geethalakshmi and M. Kavitha, "Comparison of Reference Current Extraction Methods for Shunt Active Power Filters", International Journal of Computer and Electrical Engineering, Vol. 3, No. 3, June 2011.

[15] Mehmet Ucar, Engin Ozdemir, "Control of a 3-Phase 4-Leg Active Power Filter under Non-Ideal Mains Voltage Condition ", Electric Power Systems Research, No. 78, 2005, pp. 58-73.

[16] H. Y. Kanaan, S. Georges, A. Hayek and K. Al-Haddad, "Modeling and comparative evaluation of control techniques applied to a PWM three-phase four-wire shunt active power filter", in Proc. $1^{\text {st }}$ IEEE Conference on Industrial Electronics and Applications (ICIEA'06), Singapore, May 24-26, 2006, pp. 1-6.

[17] Nohra, A.F.H.; Kanaan, H.Y.; Al-Haddad, K., "A Four-leg active power filter for harmonic mitigation and reactive power compensation in unbalanced loads systems using CFL technology," IEEE International Conference on Industrial Technology (ICIT), 2013 , vol., no., pp.1934,1939, 25-28 Feb. 2013

[18] Tri D. Rachmildha, Ana Llor, Maurice Fadel, Pekik A. Dahono, Yanuarsyah Haroen, Quasi Hybrid Direct Power Control on 3Phase 4-Wire Active Power Filter, Proceedings of the International Conference on Electrical Engineering and Informatics Institut Teknologi Bandung, Indonesia June 17-19, 2007.

[19] Tri D. Rachmildha, Ana Llor, Maurice Fadel, Pekik A. Dahono, YanuarsyahHaroen, 3-Phase 4-Wire Active Power Filter using pq-r Instantaneous Power Theory with Hybrid Approach, Jurtek UI, March2008.

[20] Tri D. Rachmildha, Ana Llor, Maurice Fadel, Pekik A. Dahono, Yanuarsyah Haroen, Hybrid Direct Power Control using p-q-r 
Power Theory Applied on 3-Phase 4-Wire Active Power, PESC 2008, Conference Proceeding, Rhode Islands, Greece, 2008.

[21] Tri D. Rachmildha, Ana Llor, Maurice Fadel, Pekik A. Dahono, Yanuarsyah Haroen, "Comparison of Direct Power Control with Hybrid Approach on 3-Phase 4-Wire Active Power Filter between p-q-0 and p-q-r Power Theory", ISIE 2008, Cambridge, 2008.

[22] Holtz, J., "Pulsewidth modulation-a survey," Power Electronics Specialists Conference, 1992. PESC '92 Record, 23rd Annual IEEE, vol., no., pp.11,18 vol.1, 29 June-3 July, 1992.

[23] Tolbert, L.M.; Fang Zheng Peng; Habetler, T.G., "Multilevel PWM methods at low modulation indices," Power Electronics, IEEE Transactions on , vol.15, no.4, pp.719-725, July 2000.

[24] A. Hanna Nohra, H. Y. Kanaan and M. Fadel, "A FlyingCapacitor-Based Multilevel Shunt Active Power Filter for Power Quality Improvement Under Severe Operating Conditions", in Proc. $2^{\text {nd }}$ International Conference on Renewable Energies for Developing Countries (REDEC'14), Beirut, Lebanon, November 26-27, 2014.

[25] A. F. Hanna Nohra, H. Y. Kanaan and M. Fadel, "A Novel Control Strategy for a Three-Phase Four-Wire Shunt Active Power Filter", in Proc. $2^{\text {nd }}$ IEEE Conference on Power Engineering and Renewable Energy (ICPERE'14), Bali, Indonesia, December 9-11, 2014.

[26] H. Y. Kanaan, S. Georges, N. Mendalek, A. Hayek and K. AlHaddad, "A Linear Decoupling Control for a PWM Three-Phase Four-Wire Shunt Active Power Filter", in Proc. 14th IEEE Mediterranean Electrotechnical Conference (MELECON'08), Ajaccio, France, May 5-7, 2008.

[27] N. Mendalek, K. Al-Haddad, H. Kanaan and G. Hassoun, "Sliding Mode Control of Three-Phase Four-Leg Shunt Active Power Filter", in Proc. 39 $9^{\text {th }}$ IEEE Power Electronics Specialists Conference (PESC'08), Rhodes, Greece, June 15-19, 2008.

[28] H. Y. Kanaan, A. Hayek and K. Al-Haddad, "Nonlinear Control Design for a PWM Three-Phase Four-Wire Shunt Active Power Filter Based on the State-Space Averaged Model", in Proc. $12^{\text {th }}$ International Conference on Harmonics and Quality of Power (ICHQP'06), Cascais, Portugal, October 01-05, 2006.

[29] H. Y. Kanaan, A. Hayek and K. Al-Haddad, "Averaged-ModelBased Nonlinear Control of a PWM Three-Phase Four-Leg Shunt Active Power Filter", in Proc. $20^{\text {th }}$ IEEE Canadian Conference on Electrical and Computer Engineering (CCECE'07), Vancouver, BC, Canada, April 22-26, 2007.

[30] H. Y. Kanaan, A. Hayek and K. Al-Haddad, "Small-Signal Average Modeling, Simulation and Carrier-Based Linear Control of a Three-Phase Four-Leg Shunt Active Power Filter", in Proc. IEEE International Electric Machines and Drives Conference (IEMDC'07), Antalya, Turkey, vol. 1, May 3-5, 2007, pp. 601607.

[31] H. Y. Kanaan, A. Hayek, K. Al-Haddad and S. Rahmani, "CarrierBased Linear Decoupling Control of a Three-Phase Four-Leg
Shunt Active Power Filter", in Proc. $33^{\text {rd }}$ Annual Conference of the IEEE Industrial Electronics (IECON'07), Taipei, Taiwan, November 5-8, 2007.

[32] H. Y. Kanaan, A. Hayek and K. Al-Haddad, "Average Modeling and Carrier-Based Control Strategies Applied to a Three-Phase 4Leg Active Power Filter", accepted in Proc. ELECTRIMACS'08, Quebec, Canada, June 8-11, 2008.

[33] H. Y. Kanaan, A. Hayek, S. Georges and K. Al-Haddad, "Averaged Modelling, Simulation and Linear Control Design of a PWM Fixed Frequency Three-Phase Four-Wire Shunt Active Power Filter for a Typical Industrial Load", in Proc. $3^{\text {rd }} I E E$ International Conference on Power Electronics, Machines and Drives (PEMD'06), Dublin, Ireland, April 04-06, 2006, pp. 252256.

[34] S. Rahmani, K. Al-Haddad and H. Y. Kanaan, "Average Modeling and Hybrid Control of a Three-Phase Series Hybrid Power Filter", in Proc. IEEE International Symposium on Industrial Electronics (ISIE'06), Montreal, Quebec, Canada, vol. 2, July 09-13, 2006 , pp. 919-924.

[35] H. Y. Kanaan, S. Rahmani and K. Al-Haddad, "New Modeling, Simulation and Control of a PWM Single-Phase Shunt Hybrid Power Filter", in Proc. IEEE International Symposium on Industrial Electronics (ISIE'06), Montreal, Quebec, Canada, vol. 2, July 09-13, 2006, pp. 960-963.

[36] S. Rahmani, K. Al-Haddad and H. Y. Kanaan, "A Comparative Study of Shunt Hybrid and Shunt Active Power Filters for SinglePhase Applications: Simulation and Experimental Validation", Journal of Mathematics and Computers in Simulation (IMACS), special issue on Modeling and Simulation of Electric Machines, Converters and Systems, Elsevier, vol.71, No.4-6, June 2006, pp. 345-359.

[37] A. Hamadi, K. Al-Haddad, S. Rahmani and H. Kanaan, "Comparison of fuzzy logic and proportional integral controller of voltage source active filter compensating current harmonics and power factor', in Proc. IEEE ICIT'04, Hammamet, Tunisia, December 8-10, 2004, vol. 2, pp. 645-650.

[38] S. Rahmani, K. Al-Haddad and H. Y. Kanaan, "Two PWM techniques for single-phase shunt active power filters employing a direct current control strategy", IET Proceedings - Power Electronics, Vol. 1, No. 3, September 2008, pp. 376-385.

[39] S. Rahmani, K. Al-Haddad, H. Y. Kanaan and F. Fnaiech, "A Comparative Study of Two PWM Techniques for Single-Phase Shunt Active Power Filters Employing Direct Current Control Strategy", in Proc. IEEE PESC'05, Recife, Brazil, June 12-16, 2005, pp. 2758-2763.

[40] S. Rahmani, K. Al-Haddad and H. Y. Kanaan, "Simulation and Experimental Design of a Modified PWM with an Indirect Current Control Technique Applied to a Single-Phase Shunt Active Power Filter", in Proc. IEEE ISIE'05, Dubrovnik, Croatia, June 20-23, 2005, vol. 2, pp. 519-524. 